\title{
Variation of Milling and Grain Physical Quality of Dry Season Pathum Thani 1 in Thailand
}

\author{
Thitinan Sreethong ${ }^{1}$, Chanakan Prom-u-thai ${ }^{1,2^{*}}$, Benjavan Rerkasem ${ }^{3}$, \\ Bernard Dell ${ }^{4}$, and Sansanee Jamjod ${ }^{1,2^{*}}$
}

\author{
${ }^{1}$ Agronomy Division, Department of Plant and Soil Sciences, Faculty of Agriculture, Chiang \\ Mai University, Chiang Mai 50200, Thailand \\ ${ }^{2}$ Lanna Rice Research Center, Chiang Mai University, Chiang Mai 50200, Thailand \\ ${ }^{3}$ Plant Genetic Research and Nutrition Laboratory, Chiang Mai University, Chiang Mai \\ 50200, Thailand \\ ${ }^{4}$ School of Veterinary and life Sciences, Murdoch University, Western Australia 6150, Australia \\ *Corresponding author.E-mail: sansanee.cm@gmail.com \\ https://doi.org/10.12982/CMUJNS.2018.0014
}

\begin{abstract}
Pathum Thani 1 (PTT1) is a photoperiod-insensitive, aromatic Thai rice variety that is grown year-round. The rice from some locations is often priced lower than others due to sub-standard grain quality. This study sought to determine the limiting grain quality characteristic(s) in dry season PTT1 and their distribution across Thailand's irrigated rice regions. To do so, we evaluated the milling and physical quality of milled rice grain of dry season PTT1 from 24 provinces in 5 regions in Thailand. Sixty-seven paddy rice samples were collected and evaluated for head rice yield, chalkiness, whiteness, and translucency. Head rice yield varied by region, with the highest (48.1\%) found in samples from the Central region, compared to 34.5-39.7\% elsewhere. Head rice chalkiness was the physical quality that varied more widely among the provinces within each region than among regions, with chalkiness at a level that would adversely affect price in more than one-half of the samples. Contrary to the general perception that chalky grain is less resistant in milling, head rice yield actually increased with total chalkiness, expressed as \% chalky grain by weight. The total chalkiness correlated negatively with translucency, while the head rice chalkiness correlated positively with whiteness. Grain chalkiness was identified as the grain quality attribute of PTT1 rice that varied with location; this directly affected the price of milled rice grain, as well as indirectly through its relationship with head rice yield and visual appearance of the milled rice grain.
\end{abstract}

Keywords: Head rice yield, Chalkiness, Location 


\section{INTRODUCTION}

Rice price is based on grain quality, which is determined by milling quality, physical appearance, and cooking quality (Efferson, 1985; Unnevehr, 1986). Milling quality is judged mainly by the yield of head rice, which is the proportion of the grain that retains at least threequarters of its length after milling. Physical quality of milled rice is determined by absence of grain chalkiness, translucency, and grain length and shape. Cooking and eating quality are indicated by amylose content of the starchy endosperm, gelatinization temperature (measured by alkaline spreading assay), and gel consistency; these all affect the characteristics of cooked rice.

Consumers generally prefer milled or white rice. It is produced by removing the hull of rough rice, followed by milling, which removes the bran layer and germ by polishing. The market value and price of milled rice grain is based on its visual appearance. Grain chalkiness is one of the physical quality determinants of milled rice in both international and domestic rice markets (Efferson, 1985; Sriswasdilek et al., 1992); chalkiness is considered a contaminant that damages the overall appearance and uniformity of milled rice (Webb, 1985; Fitzgerald et al., 2009). Moreover, chalky rice grains tend to be more brittle than completely translucent grains (Tamaki et al., 2006), and are likely to break more easily during milling, consequently producing lower head rice yield (Cooper et al., 2008; Zhou et al., 2015). The official Thai Rice Standards stipulate that White Rice 100\% grade A shall not exceed 3\% in chalky grain and $4 \%$ in broken grain (Ministry of Commerce, 1997). Milled rice with 3-6\% chalky grain and $4-4.5 \%$ broken grain is downgraded to the lower-priced grade B; beyond these percentages, it is downgraded even further.

PTT1 is an aromatic modern rice variety, known in the international milled rice trade as "Thai Pathumthani Fragrant Rice" or TPF, and domestically simply as fragrant rice, with cooking quality and price approaching, but not quite matching, the premium priced Thai Hom Mali rice. PTT1 is a semi-dwarf, photoperiod-insensitive, rice variety that can be grown yearround; it is widely grown in the dry season in Thailand's irrigated rice areas. In irrigated areas with enough water supply during the dry season, the paddy rice of PTT1 has some $20 \%$ price advantage over non-aromatic, high-yielding varieties. However, our preliminary interviews with millers and farmers have revealed that farmers in some locations are unable to take advantage of this photoperiod-insensitive, aromatic rice variety as a dry season crop due to sub-standard grain quality. Our preliminary study in June 2015 found $7 \pm 3$ chalky grains per 100 in the milled rice produced from PTT1 sold in the retail market in Chiang Mai as fragrant rice (Kao Hom $)$ at $73 \%$ of the price for Thai Hom Mali $100 \%$ (T. Sreethong unpublished).

This study set out to determine the limiting grain quality characteristic(s) in dry season PTT1 and their distribution across Thailand's irrigated rice regions.

\section{MATERIALS AND METHODS}

\section{Sampling area and verification of the variety}

Dry season rice fields growing PTT1 were surveyed in the summer season 2011, covering 24 provinces in 5 regions (Figure1). Paddy rice samples of approximately $500 \mathrm{~g}$ were collected from fields belonging to farmers, regional Rice Seed Centers, and Rice Research Centers of the Rice Department. The samples were cleaned and air dried at room temperature until the moisture content was lowered to approximately $14 \%$ wet basis before 
use. Subsamples were taken to measure grain length and width with a digital calliper vernier, alkaline spreading value, and amylose content (Little, 1958; Juliano, 1971). Samples that did not meet the Ministry of Commerce standard for Thai Pathumthani Fragrant Rice (Ministry of Commerce, 2004) in dimension of brown rice and the physicochemical properties were eliminated from the remaining evaluation.

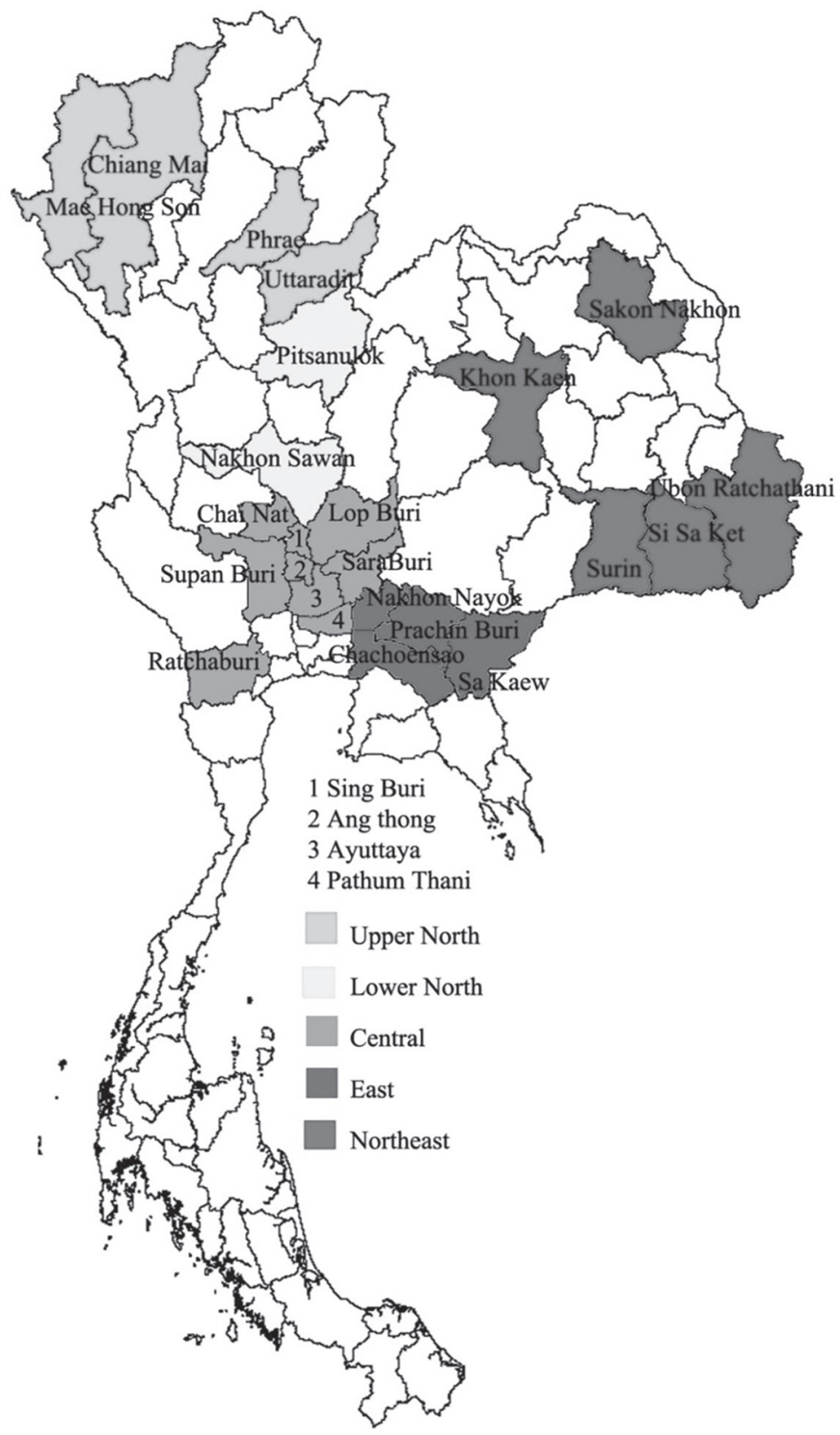

Figure 1. Map of PTT1 rice sampling area grown in the dry season 2011 from different regions in Thailand.

Note: Provinces grouped according to the Rice Zoning regions by the Rice Department, Ministry of Agriculture and Cooperatives. 


\section{Measurement of milling and grain physical quality}

Samples $(100 \mathrm{~g})$ of the paddy rice were dehulled in a testing dehuller (NgekSengHuat, model P-1) to yield brown rice. The brown rice samples were weighed and milled for 30 seconds in a laboratory milling machine (NgekSengHuat, model K-1) to produce milled or white rice. Each sample was processed in three replications.

A subsample of 10-15 grams of milled rice from each sample was separated into head rice ( $\geq 3 / 4$ length of whole milled grain) and broken rice. All fractions were weighed to determine the percentage of head rice based on paddy rice weight. Grain chalkiness is defined as the visually detectable opaque region in an otherwise translucent background of a milled rice grain, and expressed in two ways. Head rice chalkiness was determined as the number of grains out of 100 randomly selected head rice grains with a chalky area of one-half or more of the kernel, as described in the official Thai rice quality standard (Ministry of Commerce, 1997), expressed as head rice chalkiness, \% by number. Total chalkiness was determined as the percentage by weight of milled grain with visually detectable chalky region in the head rice plus broken rice grain, and expressed as total chalkiness (\% by weight) (Figure 2). Grain whiteness and translucency were determined by using a milling meter (Satake, model MM1D), with specification for whiteness at 5.0-70.0\% and transparency at $0.01-8.00 \%$.

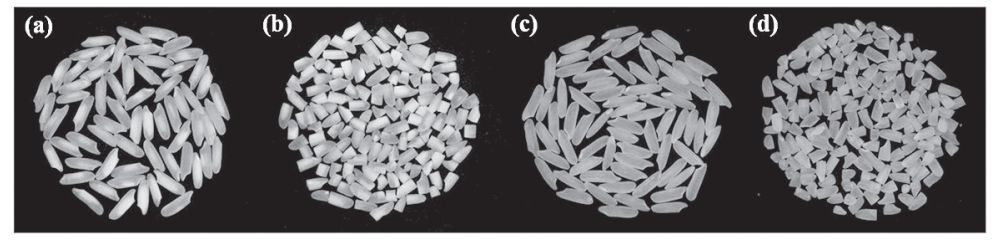

Figure 2. Visually detectable chalky grain in head rice (a) and broken rice (b), non-chalky head rice (c), and broken rice (d).

\section{RESULTS}

\section{Brown rice grain dimension and chemical property of dry season PTT1}

Sixty-seven samples were collected from the surveyed regions, 8 samples from Upper North, 6 samples from Lower North, 35 samples from Central, 11 from East, and 7 samples from Northeast that fell within the standard for Thai Pathumthani Fragrant Rice of the Ministry of Commerce (Ministry of Commerce, 2004) (Table 1). The brown rice of all samples ranged in grain length from 7.35-7.58 mm, with grain shape as described by the length-to-width ratio ranging from 3.30-3.40. The amylose content ranged from 16.6-18.6\% and alkaline spreading value from $6.4-6.8 \%$. 
Table 1. The dimensions and chemical properties of the brown rice grain of variety PTT1 grown in the dry season 2011 from different regions of Thailand.

\begin{tabular}{lccccc}
\hline \multirow{2}{*}{ Region } & $\begin{array}{c}\text { Number } \\
\text { of }\end{array}$ & $\begin{array}{c}\text { Brown rice grain dimension } \\
\text { samples }\end{array}$ & Length (mm) & Length/width & Chemical property \\
\cline { 3 - 6 } & & & & & $\begin{array}{c}\text { Alkaline } \\
\text { spreading } \\
\text { value }\end{array}$ \\
\hline Upper North & 8 & $7.58 \pm 0.20$ & $3.34 \pm 0.13$ & $18.6 \pm 1.6$ & $6.4 \pm 0.2$ \\
Lower North & 6 & $7.53 \pm 0.18$ & $3.34 \pm 0.12$ & $17.0 \pm 0.7$ & $6.4 \pm 0.2$ \\
Central & 35 & $7.35 \pm 0.19$ & $3.40 \pm 0.11$ & $17.5 \pm 0.8$ & $6.4 \pm 0.2$ \\
East & 11 & $7.50 \pm 0.18$ & $3.30 \pm 0.11$ & $16.6 \pm 1.1$ & $6.5 \pm 0.3$ \\
Northeast & 7 & $7.39 \pm 0.25$ & $3.38 \pm 0.11$ & $18.5 \pm 0.9$ & $6.8 \pm 0.1$ \\
\hline Standard of PTT1 ${ }^{1}$ & 67 & $>7.00$ & $>3.20$ & $16.0-20.0$ & $6.0-7.0$ \\
\hline
\end{tabular}

Note: \pm standard deviation. ${ }^{1}$ As described in Ministry of Commerce Thai rice standard 2004 (Ministry of Commerce, 2004).

\section{Variation in grain quality characteristics, by region and province}

More than one-half of the samples produced head rice yield that was $>40 \%$, but with significant variation among the regions (Table 2). The Central region produced the highest head rice yield with an average of $48.1 \%$, while the other regions averaged $34.5-39.7 \%$. However, significant variation was also found in the head rice yield from different provinces in each region (Figure 3a). For example, while the head rice yield in all other provinces in the Central region exceeded $40 \%$, the rice from Chai Nat had much lower head rice yield. Large variation in head rice yield was also found among the provinces of the Upper North, Lower North, and East. Head rice yield between provinces ranged from 22.8-54.6\%. The standard deviation was high in samples from Prachin Buri (9.1), followed by Chiang Mai (7.8) and Surin (7.7).

Table 2. Frequency distribution of rice samples in different class of head rice yield of the variety PTT1 grown in the dry season 2011 from different regions of Thailand.

\begin{tabular}{|c|c|c|c|c|c|c|c|}
\hline \multirow{3}{*}{ Region } & \multirow{3}{*}{$\begin{array}{c}\text { Number } \\
\text { of } \\
\text { samples }\end{array}$} & \multicolumn{2}{|c|}{ Head rice yield (\%) } & \multicolumn{4}{|c|}{ Chemical property } \\
\hline & & \multirow{2}{*}{$\operatorname{mean} \pm \mathrm{SD}$} & \multirow{2}{*}{$\% \mathrm{CV}$} & $<30 \%$ & $30-40 \%$ & $41-50 \%$ & $>\mathbf{5 0} \%$ \\
\hline & & & & \multicolumn{4}{|c|}{ \% of samples } \\
\hline Upper North & 8 & $35.3 \pm 9.0$ & 25.5 & 38 & 38 & 25 & \\
\hline Lower North & 6 & $39.7 \pm 12.3$ & 31.1 & 17 & 33 & 33 & 17 \\
\hline Central & 35 & $48.1 \pm 7.9$ & 16.5 & 3 & 14 & 34 & 49 \\
\hline East & 11 & $38.0 \pm 8.6$ & 22.5 & 9 & 55 & 27 & 9 \\
\hline Northeast & 7 & $34.5 \pm 6.4$ & 18.5 & 14 & 86 & & \\
\hline Total & 67 & $42.7 \pm 10.1$ & 23.5 & 10 & 33 & 28 & 28 \\
\hline
\end{tabular}

Note: Regional means were significantly different at $P<0.05$ by analysis of variance. 
Head rice chalkiness was highly variable among the provinces in each region, but without significant regional variation (Table 3 ). The standard for high grain quality $\leq 6.0 \%$ head rice chalkiness accounted for $46 \%$ of the samples. Within each region there was a wide range of head rice chalkiness, and also among samples from the same provinces (Figure $3 b$ ). The different of head rice chalkiness was up to 10 times between provinces. The samples from Ratchaburi had the highest average head rice chalkiness (15.3\%), while samples from Nakhon Sawan had the lowest average head rice chalkiness (1.4\%), followed by Si Sa Ket (1.8\%) and Ayuttaya (2.0\%). The standard deviation was high in samples from Surin (9.8), followed by Lop Buri (5.8) and Ratchaburi (5.4). Total chalkiness (\% by weight) was also highly variable among the provinces (data not shown).

Table 3. Frequency distribution of rice samples in different class of head rice chalkiness of the variety PTT1 grown in the dry season 2011 from different regions of Thailand.

\begin{tabular}{|c|c|c|c|c|c|c|}
\hline \multirow{3}{*}{ Region } & \multirow{3}{*}{$\begin{array}{c}\text { Number } \\
\text { of } \\
\text { samples }\end{array}$} & \multicolumn{2}{|c|}{ Head rice chalkiness $(\%)$} & \multicolumn{3}{|c|}{ Range of head rice chalkiness ${ }^{1}$} \\
\hline & & \multirow{2}{*}{ mean $\pm \mathrm{SD}$} & \multirow{2}{*}{$\% \mathrm{CV}$} & $\leq 6.0 \%$ & $6.0-7.0 \%$ & $>7.0 \%$ \\
\hline & & & & \multicolumn{3}{|c|}{$\%$ of samples } \\
\hline Upper North & 8 & $7.5 \pm 4.0$ & 53.4 & 38 & 25 & 38 \\
\hline Lower North & 6 & $4.4 \pm 3.7$ & 83.3 & 67 & & 33 \\
\hline Central & 35 & $8.6 \pm 4.8$ & 56.3 & 40 & 6 & 54 \\
\hline East & 11 & $6.2 \pm 2.7$ & 43.6 & 64 & 18 & 18 \\
\hline Northeast & 7 & $9.8 \pm 6.0$ & 61.1 & 43 & & 57 \\
\hline Total & 67 & $7.8 \pm 4.6$ & 59.1 & 46 & 9 & 45 \\
\hline
\end{tabular}

Note: ${ }^{1}$ Percentage by number of head rice grain with opaque area in $\geq$ one-half of the surface area. Regional means were not significantly different at $P<0.05$ by analysis of variance.

The samples were relatively uniform in their whiteness, which fell within the range of $35-50 \%$, with more than one-half in the $41-45 \%$ class (Table 4$)$. The regional average of whiteness ranged from $42.9-44.1 \%$, and among provinces within regions, with low $\% \mathrm{CVs}$ in whiteness that ranged from $5.4-7.9 \%$.

Table 4. Frequency distribution of rice samples in different class of whiteness of the variety PTT1 grown in the dry season 2011 from different regions of Thailand.

\begin{tabular}{|c|c|c|c|c|c|c|}
\hline \multirow{3}{*}{ Region } & \multirow{3}{*}{$\begin{array}{c}\text { Number } \\
\text { of } \\
\text { samples }\end{array}$} & \multicolumn{2}{|c|}{ Whiteness (\%) } & \multicolumn{3}{|c|}{ Range of whiteness $^{1}$} \\
\hline & & \multirow{2}{*}{ mean $\pm \mathrm{SD}$} & \multirow{2}{*}{$\% \mathrm{CV}$} & $35-40 \%$ & $41-45 \%$ & $46-50 \%$ \\
\hline & & & & \multicolumn{3}{|c|}{$\%$ of samples } \\
\hline Upper North & 8 & $43.6 \pm 3.4$ & 7.9 & 38 & 25 & 38 \\
\hline Lower North & 6 & $44.1 \pm 1.5$ & 5.4 & & 83 & 17 \\
\hline Central & 35 & $42.9 \pm 2.8$ & 6.3 & 23 & 63 & 14 \\
\hline East & 11 & $43.5 \pm 2.7$ & 6.2 & 18 & 64 & 18 \\
\hline Northeast & 7 & $43.7 \pm 2.7$ & 6.2 & 29 & 57 & 14 \\
\hline Total & 67 & $43.3 \pm 2.7$ & 6.3 & 22 & 60 & 18 \\
\hline
\end{tabular}

Note: ${ }^{15.0 \%}=$ least bright; $70.0 \%=$ most bright. Regional means were not significantly different at $P<0.05$ by analysis of variance. 
The translucency of the samples was distributed largely within the range of $2.01-4.00 \%$ (Table 5). The middle range of 2.01-3.00\% translucency accounted for three quarters of the samples. The regions were distinguishable by their average translucency of milled rice, with the highest in samples from the Upper North (2.96\%), Northeast (2.86\%), and East $(2.72 \%)$. Similar levels of variation occurred among the provinces within regions, with the $\% \mathrm{CVs}$ ranging from $10.6 \%$ in the Upper North to $17.4 \%$ in the Lower North.

Table 5. Frequency distribution of rice samples in different class of translucency of the variety PTT1 grown in the dry season 2011 from different regions of Thailand.

\begin{tabular}{|c|c|c|c|c|c|c|}
\hline \multirow{3}{*}{ Region } & \multirow{3}{*}{$\begin{array}{c}\text { Number } \\
\text { of } \\
\text { samples }\end{array}$} & \multicolumn{2}{|c|}{ Translucency (\%) } & \multicolumn{3}{|c|}{ Range of translucency ${ }^{1}$} \\
\hline & & \multirow{2}{*}{ mean $\pm \mathrm{SD}$} & \multirow{2}{*}{$\% \mathrm{CV}$} & $1.00-2.00 \%$ & $2.01-3.00 \%$ & $3.01-4.00 \%$ \\
\hline & & & & \multicolumn{3}{|c|}{$\%$ of samples } \\
\hline Upper North & 8 & $2.96 \pm 0.31$ & 10.6 & & 63 & 38 \\
\hline Lower North & 6 & $2.51 \pm 0.44$ & 17.4 & & 67 & 33 \\
\hline Central & 35 & $2.61 \pm 0.29$ & 11.1 & 3 & 83 & 14 \\
\hline East & 11 & $2.72 \pm 0.37$ & 13.6 & & 82 & 18 \\
\hline Northeast & 7 & $2.86 \pm 0.34$ & 12.0 & & 43 & 57 \\
\hline Total & 67 & $2.69 \pm 0.34$ & 12.8 & 1 & 75 & 24 \\
\hline
\end{tabular}

Note: ${ }^{1} 0.01 \%=$ least transparent; $8.00 \%=$ most transparent. Regional means were significantly different at $P<0.05$ by analysis of variance.

\section{Relationship between grain quality characteristics}

Head rice yield was significantly correlated with total chalkiness ( $\%$ by weight) $(P<0.05)$ but not with head rice chalkiness $(\%$ by number) (Table 6$)$. Among the different grain quality characteristics there was a significant correlation $(P<0.05)$ between head rice chalkiness ( $\%$ by number) and whiteness, while total chalkiness ( $\%$ by weight) was correlated negatively with translucency (Table 6).

Table 6. Correlation between head rice yield, chalkiness, whiteness, and translucency of the variety PTT1 grown in the dry season 2011 in Thailand.

\begin{tabular}{lcccc}
\hline & $\begin{array}{c}\text { Head rice } \\
\text { chalkiness } \\
(\% \text { by number })\end{array}$ & $\begin{array}{c}\text { Total chalkiness } \\
\text { (\% by weight) }\end{array}$ & $\begin{array}{c}\text { Head rice yield } \\
(\%)\end{array}$ & $\begin{array}{c}\text { Whiteness } \\
(\%)\end{array}$ \\
\hline $\begin{array}{l}\text { Total chalkiness } \\
\text { (\% by weight) }\end{array}$ & $0.38^{\mathrm{ns}}$ & & & \\
Head rice yield (\%) & $-0.06^{\mathrm{ns}}$ & $0.42^{*}$ & & \\
Whiteness (\%) & $0.51^{*}$ & $0.14^{\mathrm{ns}}$ & $-0.14^{\mathrm{ns}}$ & \\
Translucency (\%) & $0.09^{\mathrm{ns}}$ & $-0.56^{*}$ & $0.09^{\mathrm{ns}}$ & $0.15^{\mathrm{ns}}$ \\
\hline
\end{tabular}

Note: *indicates significant difference at $P<0.05$; ns indicates no significant difference. 


\section{DISCUSSION}

The grain quality characteristics that are determinants of prices (Leesawatwong et al., 2003) of the dry season PPT1 rice in this study were found to vary differently across the growing regions, with grain chalkiness being the most variable, followed by head rice yield and translucency, with whiteness the least variable.

The resistance of the grain during milling, which determines head rice yield, is influenced by both genetic and environmental factors (Khush et al., 1979; Juliano et al., 1993; Zhao and Fitzgerald, 2013). This study found that the samples of PTT1 from the Central region had higher head rice yield than the other regions. Variation of head rice yield grown in different locations has been reported in another rice variety. Thai Jasmine rice or Khao Dawk Mali 105 rice variety from Nakorn Sawan (Lower North region) had higher head rice yield than samples from Chiang Mai (Upper North region) (Leesawatwong et al., 2003). The standard used in the paddy rice market in Thailand for head rice yield is 30-40\%, and paddy with $<20 \%$ head rice yield may be rejected or sold as sub-standard, broken rice (Prom-U-Thai, 2010). While this study found significant regional variation, all samples but one exceeded this standard.

The presence of chalky grain is detrimental to the uniformity of milled rice (Webb, 1985; Fitzgerald et al., 2009). The two ways in which grain chalkiness were measured and expressed in this study had different implications. Expressed as number of grains with $>50 \%$ chalky area per 100, one of the quality measures defining grade and price of Thai rice (Ministry of Commerce, 1997; 2004), the head rice chalkiness of dry season PTT1 was found to vary widely among provinces. A large gradient of environmental factors and agronomic practices contribute to grain chalkiness (Tashiro and Morie, 1979; Zhang et al., 2008; Lanning et al., 2011; Qiao et al., 2011). The standard for "Thai Pathumthani Fragrant Rice" (TPF) stipulates that TPF $100 \%$ shall not contain more than 6 chalky grains per 100, while the PTT1 milled rice TPF with more than 7\% of chalky grains per 100 is downgraded to TPF 5\% (Ministry of Commerce, 2004).

Although, samples from the Central region, where the bulk of Thailand's dry season rice is produced, showed high head rice yield, more than one-half of the samples from this region did not make the grade of TPF $100 \%$, with more than 7 chalky head rice grains per 100 . The head rice chalkiness correlated significantly with whiteness, another quality attribute important in rice marketing. Fertilizer application and water management has been reported to lower grain chalkiness. Raising the rate of nitrogen fertilizer from $90 \mathrm{~kg} / \mathrm{ha}$ to $270 \mathrm{~kg} /$ ha reduced grain chalkiness from $27 \%$ to $15 \%$ in the rice variety 9522 (Qiao, et al., 2011). Similarly, topdressing with nitrogen fertilizer at flowering reduced grain chalkiness to $33 \%$ compared to $65 \%$ without nitrogen fertilization (Tashiro and Morie, 1979). Also, alternate soil wetting and drying during grain filling lowered grain chalkiness (Zhang et al., 2008). Drainage of water before harvest lowered chalkiness in one variety but not the other variety of deep water rice (Bangwaek, 1994). It is remains to be seen how grain chalkiness in PTT1 may respond to these management practices.

Grain chalkiness has been explained by the loose packing of starch granules and protein bodies and a result of many air spaces in the endosperm structure, consequently chalky grain is less resistant than translucent grain and is more readily broken during milling (Del Rosario, 1968; Tamaki et al., 2006). This is contradicted by the positive correlation 
between total chalkiness and head rice yield in the present study. The grain filling process is complicated and associated with many physiological processes (Tsukaguchi and Iida, 2008; Liu et al., 2010; Wada et al., 2014). Grain chalkiness may involve changes in internal structure with complex relationships with milling resistance. Further complexity was indicated by the different ways in which grain chalkiness was associated with other quality attributes: total chalkiness positively correlated with head rice yield and negatively with translucency; and head rice chalkiness positively correlated with whiteness. Determination of quality for market value of the grain may need to be differentiated from precise measures of quality attributes aimed at elucidating the underlying processes.

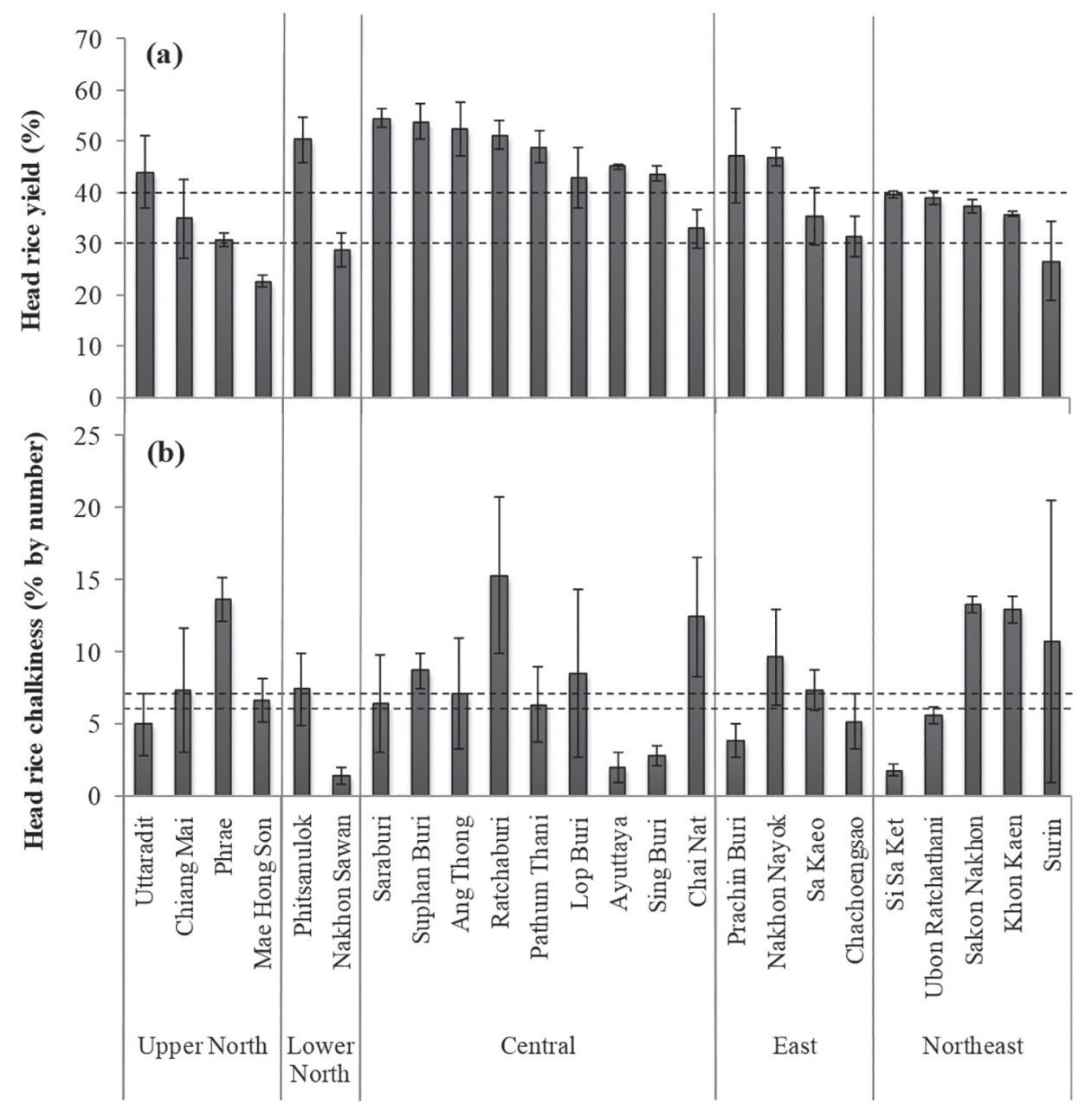

Figure 3. Head rice yield (a) and head rice chalkiness (b) (\% of grains with opaque region in one-half or more of the surface area milled rice kernel by number) of dry season PTT1 rice samples from different provinces in five Rice Zoning regions of Thailand (with standard deviation bars). 


\section{ACKNOWLEDGEMENTS}

We would like to thank the farmers and Regional Rice Seed Centers and Rice Research Centers for the PTT1 paddy rice samples. The first author is a recipient of a Royal Golden Jubilee $\mathrm{PhD}$ scholarship.

\section{REFERENCES}

Bangwaek, C. 1994. Factors affecting grain chalkiness in deepwater and floating rice (Oryza sativa L.). Ph.D. Dissertation, University of the Philippines Los Baños, Philippines.

Cooper, N.T.W., Siebenmorgen, T. J., and Counce, P.A. 2008. Effects of nighttime temperature during kernel development on rice physicochemical properties. Cereal Chemistry. 85(3): 276-282. http://dx.doi.org/10.1094/CCHEM-85-3-0276

Del Rosario, A.R., Briones,V.P., Vidal, A.J., and Juliano, B.O. 1968. Composition and endosperm structure of developing and mature rice kernel. Cereal Chemistry. 45: 225235.

Efferson, J.N. 1985. Rice quality in world markets. p.1-13. In: Rice Grain Quality and Marketing, the International Rice Research Conference. Manila, 1-5 Jun 1985.

Fitzgerald, M.A., McCouch, S.R., and Hall, R.D. 2009. Not just a grain of rice: the quest for quality. Trends in Plant Science. 14(3): 133-139. http://doi.org/10.1016/j.tplants. 2008.12.004

Juliano, B., Perez, C., and Cuevas-Perez, F. 1993. Screening for stable high head rice yields in rough rice. Cereal chemistry. 70(6): 650-655.

Juliano, B.O. 1971. A simplified assay for milled-rice amylose. Cereal Science Today. 16: 334-336.

Khush, G.S., Paule, C.M., and De La Cruz, N.M. 1979. Rice grain quality evaluation and improvement at IRRI. p.21-32. In: Proceeding of the workshop on chemical aspects in rice grain quality. Los Baños, Laguna, 23-25 Oct 1978.

Lanning, S.B., Siebenmorgen, T.J., Counce, P.A., Ambardekar, A.A., and Mauromoustakos, A. 2011. Extreme nighttime air temperatures in 2010 impact rice chalkiness and milling quality. Field Crops Research. 124(1): 132-136. https://doi.org/10.1016/j. fcr.2011.06.012

Leesawatwong, M., Jamjod S., Rerkasem B., and Pinjai, S. 2003. Determinants of a premiumpriced, special-quality rice. International Rice Research Notes. 28(1): 3.

Little, R.R., Hilder, G.B., and Dawson, E.H. 1958. Differential effect of dilute alkaline on 25 varieties of milled white rice. Cereal Chemistry. 35: 111-126.

Liu, X., Guo, T., Wan, X., Wang, H., Zhu, M., Li, A., Su, N., Shen, Y., Mao, B., Zhai, H., et al., 2010. Transcriptome analysis of grain-filling caryopses reveals involvement of multiple regulatory pathways in chalky grain formation in rice. BMC Genomics. 11(1): 1-15. https://doi.org/10.1186/1471-2164-11-730 
Ministry of Commerce. 1997. Rice standards B.E. 2540, Ministerial Announcement, Goverment of Thailand.

Ministry of Commerce. 2004. Notification of the Commerce: Prescribing the standard of Pathumthani Fragrant Rice, B.E. 2544. The Goverment Gazette.

Prom-U-Thai, C. 2010. Case study 10: Rice quality evaluation. Agricultural Research for Local Solution and Opportunities project, Public Policy Studies Institute, Chiang Mai University.

Qiao, J., Liu, Z., Deng, S., Ning, H., Yang, X., Lin, Z., Li, G., Wang, Q., Wang, S., and Ding, Y. 2011. Occurrence of perfect and imperfect grains of six japonica rice cultivars as affected by nitrogen fertilization. Plant and Soil. 349(1): 191-202. https://doi. org/10.1007/s11104-011-0861-4

Sriswasdilek, J., Kongseree, N., and Attaviriyasook, K. 1992. Rice quality in the retail level: rice grain characteristics affecting retail price in Thailand. p.97-108. In: Unnevehr, L.J., B. Duff, and Juliano, B.O. (eds) Consumer demand for rice grain quality, terminal report of IDRC projects National Grain Quality (Asia) and International Grain Grain quality Economics (Asia), International Rice Research Institute, International Development Research Centre.

Tamaki, M., Kurita, S., Toyomaru, M., Itani, T., Tsuchiya, T., Aramaki, I., and Okuda, M. 2006. Difference in the physical properties of white-core and non-white-core kernels of the rice varieties for sake brewing is unrelated to starch properties. Plant Production Science. 9(1): 78-82. http://doi.org/10.1626/pps.9.78

Tashiro, T., and Morie, E. 1979. Studies on white-belly kernel. VI. Effect of nitrogen topdressing at heading stage on the occurrence of white-belly kernel. Japanese Journal of Crop Science. 48(1): 99-106. https://doi.org/10.1626/jcs.48.99

Tsukaguchi, T., and Iida, Y. 2008. Effects of assimilate supply and high temperature during grain-filling period on the occurrence of various types of chalky kernels in rice plants (Oryza sativa L.). Plant Production Science. 11(2): 203-210. http://doi.org/10.1626/ pps. 11.23

Unnevehr, L.J. 1986. Consumer demand for rice grain quality and returns to research for quality improvement in Southeast Asia. American Journal of Agricultural Economics. 68(3): 634-641.

Wada, H., Masumoto-Kubo, C., Gholipour, Y., Nonami, H., Tanaka, F., Erra-Balsells, R., Tsutsumi, K., Hiraoka, K., and Morita, S. 2014. Rice chalky ring formation caused by temporal reduction in starch biosynthesis during osmotic adjustment under foehn-induced dry wind. PloS One. 9(10): e110374. https://doi.org/10.1371/journal. pone. 0110374

Webb, B. D. 1985. Criteria of rice quality in the United States. p.403-442. In Juliano, B.O. (ed) Rice: Chemistry and Technology $2^{\text {nd }}$ ed. St. Paul, MN.

Zhang, H., Zhang, S., Yang, J., Zhang, J., and Wang, Z. 2008. Postanthesis moderate wetting drying improves both quality and quantity of rice yield. Agronomy Journal. 100(3): 726-734. http://doi.org/10.2134/agronj2007.0169 
Zhao, X., and Fitzgerald, M. 2013. Climate change: implications for the yield of edible rice. PLoS ONE. 8(6): e66218. http://doi.org/10.1371/journal.pone.0066218

Zhou, L., Liang, S., Ponce, K., Marundon, S., Ye, G., and Zhao, X. 2015. Factors affecting head rice yield and chalkiness in indica rice. Field Crops Research, 172: 1-10. https:// doi.org/10.1016/j.fcr.2014.12.004 